\title{
A Different Breed of Wolf: First Known Case of Wolf-Hirschorn Syndrome with Third-degree Atrioventricular Block Requiring Pacemaker Implantation
}

\author{
ROBERT LEE PERCELL, Jr., MD, ${ }^{1}$ HYACINTH C. PERCELL, BS, ${ }^{1}$ and KEITH A. MILLER, MD ${ }^{1}$ \\ 'Electrophysiology Section, Bryan Heart Institute, Lincoln, NE, USA
}

\begin{abstract}
We describe a case of a 44-year-old male with a history of Wolf-Hirschorn syndrome (WHS) with seizures and mental retardation who was evaluated for what was thought to be a seizure. He was found to be severely bradycardic with a heart rate of $24 \mathrm{bpm}$. The electrocardiogram revealed third-degree atrioventricular block and he subsequently underwent an uncomplicated single-chamber pacemaker implantation procedure. This is a unique report given its status as the first described case of bradycardic rhythm abnormalities in a patient with WHS.
\end{abstract}

KEYWORDS. Arrhythmia, heart block, Wolf-Hirschorn syndrome.
ISSN 2156-3977 (print) ISSN 2156-3993 (online) CC BY 4.0 license

(C) 2020 Innovations in Cardiac Rhythm Management

\section{Case presentation}

A 44-year-old Caucasian male presented to the clinic as severely disabled and nonverbal at baseline. He had a history of Wolf-Hirschorn syndrome (WSH), seizures, and mental retardation. He was reported to have displayed seizure-like activity that included the shaking of his right side, eyes rolling back into his head, and lips turning blue, which were similar to observed signs of his previous seizures. His last reported seizure was in 2017. His sister stated that she had not noticed any fever or flu-type symptoms. She feeds him baby food and he drinks out of a sippy cup. He is bedridden but can sit in a wheelchair. He had no recent rash or insect or tick exposure. There

Dr. Percell reports that he is on speaker bureaus for Abbott Medical, Biosense Webster, Janssen, Pfizer, and Boehringer Ingelheim and is the founder of the SANS FLUORO Association, outside the scope of the submitted work.

Manuscript received July 13, 2019. Final version accepted October 3, 2019.

Address correspondence to: Robert Lee Percell, Jr., MD, SANS FLUORO Association, Electrophysiology Section, Bryan Heart Institute, $1600 \mathrm{~S} 48$ th Street, Lincoln, NE 68506, USA.

Email: robertpercelljr@gmail.com. were no family members with arrhythmias or developmental disorders.

Upon arrival to the emergency department, he was found to be severely bradycardic with a heart rate of 20 to 30 bpm with third-degree atrioventricular (AV) block. The atrial rate was $120 \mathrm{bpm}$, while the junctional escape rate was $30 \mathrm{bpm}$ (Figure 1). The systolic blood pressure was $90 \mathrm{mmHg}$. He was given $1 \mathrm{~L}$ of intravenous fluids, with some response; his heart rate increased to $60 \mathrm{bpm}$ and his systolic blood pressure increased to $120 \mathrm{mmHg}$ (Figure 2). However, an hour later, his heart rate returned to $20 \mathrm{bpm}$ and his systolic blood pressure was measured as $70 \mathrm{mmHg}$.

A routine laboratory examination on admission revealed the following: elevated white blood cell count of 24.4 tho / $\mathrm{cmm}$, normal hemoglobin and hematocrit values, sodium level of $135 \mathrm{mEq} / \mathrm{L}$, potassium level of $4.6 \mathrm{mEq} / \mathrm{L}$, blood urea nitrogen level of $34 \mathrm{mg} / \mathrm{dL}$, and creatinine level of $1.8 \mathrm{mg} / \mathrm{dL}$. His troponin and thyroid-stimulating hormone levels were normal, while other laboratory findings were unremarkable. Further, the total valproic acid level was $120 \mu \mathrm{g} / \mathrm{mL}$ (therapeutic range: $50-125 \mu \mathrm{g} / \mathrm{mL}$ ). The chest radiograph was unremarkable, with normal cardiac size and clear lung fields. 


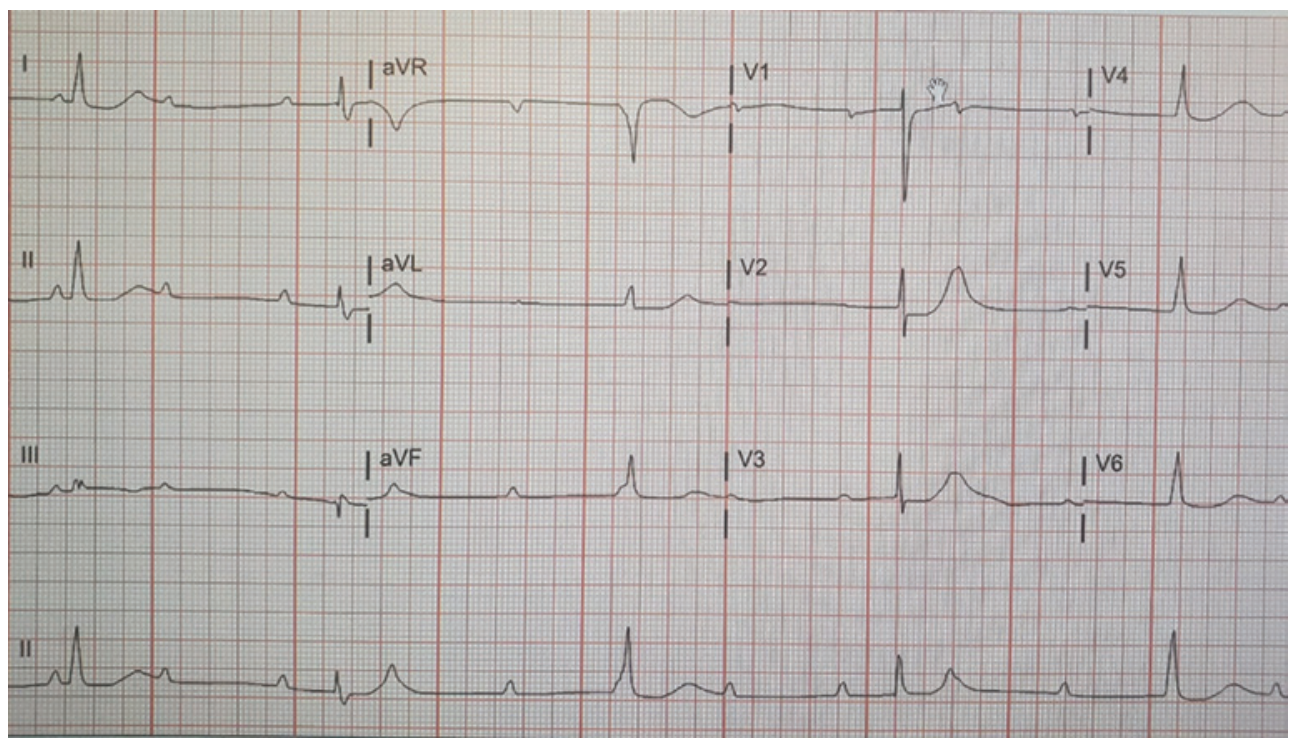

Figure 1: Initial electrocardiogram revealing third-degree AV block with an atrial rate of $75 \mathrm{bpm}$ and a junctional escape rate of $30 \mathrm{bpm}$ with a normal axis.

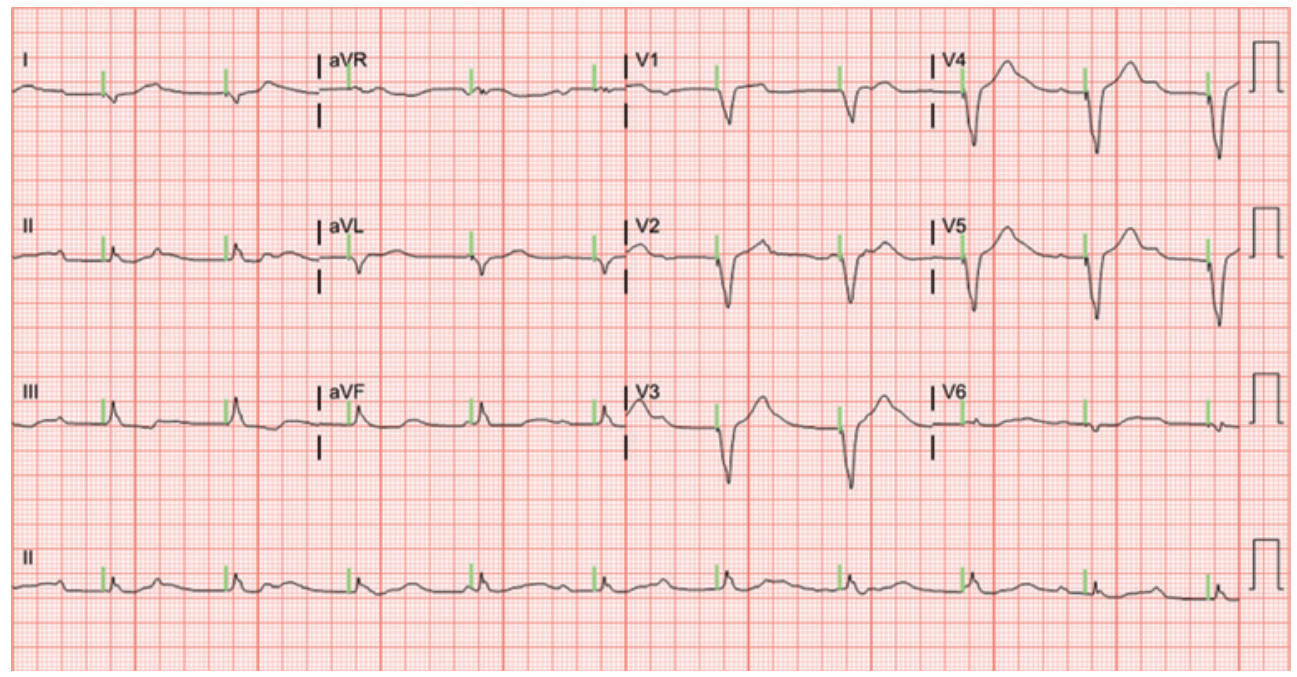

Figure 2: Electrocardiogram showing ventricular pacing with a rate of $60 \mathrm{bpm}$.

He was admitted to the intensive care unit and placed on a dopamine drip overnight. The following day, he remained in third-degree AV block. His white blood cell count had decreased to 15.7 tho/ cmm, and an echocardiogram revealed normal left ventricular systolic function with an ejection fraction of $60 \%$, with mild to moderate mitral regurgitation. There was no evidence of congenital heart disease.

After a long discussion with the family, the patient underwent uncomplicated single-chamber pacemaker implantation under general anesthesia (Figure 3). He was discharged two days later.

At the two-week follow-up checkup, the patient was $100 \%$ ventricular-paced. His caregiver reported no further episodes of seizure activity.
Unfortunately, two months later, the patient was readmitted with leukocytosis secondary to pacemaker pocket infection. Coagulase-negative staphylococcus grew from both blood and wound cultures. He was treated with cefazolin for a planned six-week course. Transthoracic echocardiogram suggested a bicuspid valve at that point.

One week after discharge, he was readmitted with a seizure and leukocytosis. Transesophageal echocardiogram revealed a definite bicuspid valve as well as extensive vegetation on the single right ventricular (RV) lead that was highly mobile and contacted the RV free wall (Figure 4). After extensive discussions with the guardian with the power of attorney regarding performing further invasive measures including extraction, he was discharged with hospice care. 


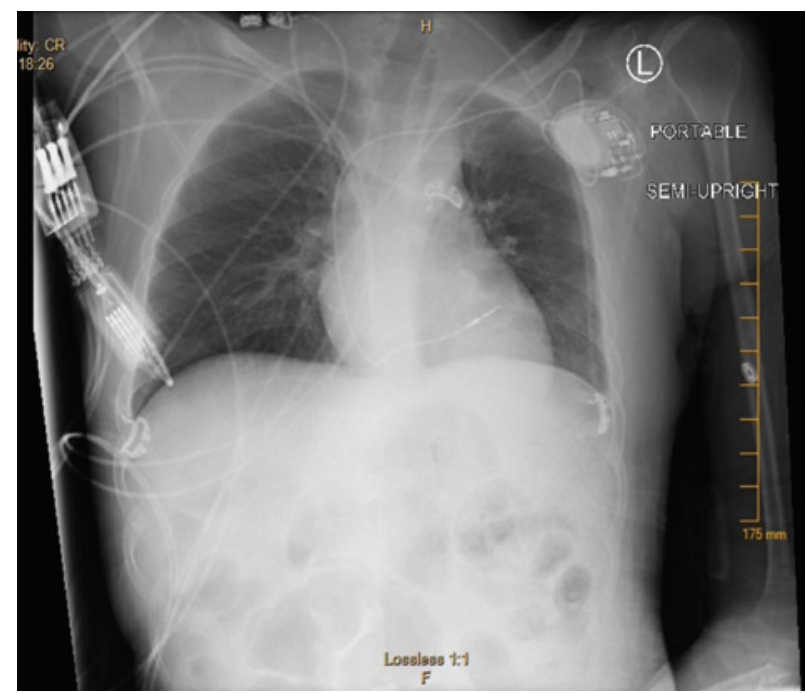

Figure 3: Chest radiograph revealing the patient's singlechamber pacemaker with the ventricular lead placed in the septum.

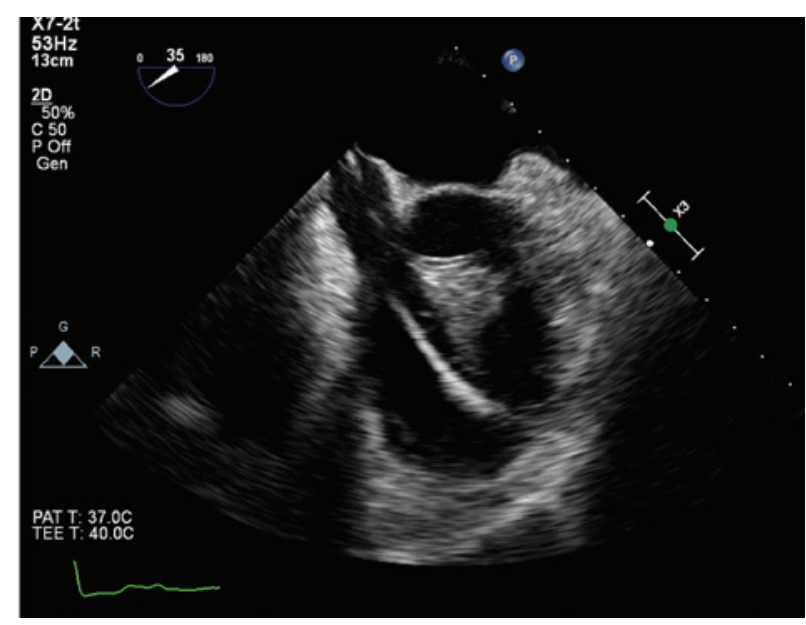

Figure 4: Transesophageal echocardiogram revealing a 3.2-cm $\times$ 2.4-cm mass attached to the RV lead, extending to the RV free wall.

\section{Discussion}

WHS is a very rare chromosomal disorder that occurs in approximately one in 20,000 to 50,000 newborns. ${ }^{1}$ It is two times more likely to be seen in females and the etiology is the terminal deletion of the short arm of chromosome $4 .^{2}$ The more significant the amount of missing chromosomal material, the larger the clinical expression of WHS that is seen is. ${ }^{3}$ This syndrome was first described by Hirschorn and Cooper. ${ }^{3}$ Wolf et al. later confirmed their findings. ${ }^{4}$

A review of 43 cases of WHS in 1976 reported a mortality rate of $34 \%$ in the first two years of life; however, a later study showed that survival increases dramatically after two years of age. ${ }^{5}$ WHS patients frequently die prematurely secondary to lower respiratory-tract infection (25\%), multiple congenital anomalies (15.6\%), sudden unexplained death $(15.6 \%)$, congenital heart disease $(15.6 \%)$, and anoxia at birth $(9.4 \%) .{ }^{5}$ Reported types of congenital heart disease have included one case of tetralogy of Fallot; two with a ventricular septal defect and patent ductus arteriosus; one with an ostium secundum atrial septal defect; and a complex case involving a double-outlet single ventricle with a single AV valve, large aorta, and small posterior pulmonary artery with pulmonary valve stenosis. There is additionally one report of a male in the Netherlands who was 58 years old as of $2014 .^{6}$

The diagnosis of WHS is initially made based on infant facial features and developmental retardation; however, it can be confirmed with genetic testing. ${ }^{7}$ There is no definite gene defect but most experts have identified the following candidate genes: WHSC1, WHC2, and fibroblast growth factor receptor 3 (FGFR3). ${ }^{8}$ The differential diagnosis includes other genetic disorders with microdeletions such as Rubinstein-Taybi syndrome, Smith-Magenis syndrome, and Pitt-Rogers-Danks syndrome. ${ }^{9}$

WHS is frequently described based on the presence of intellectual disabilities; the Greek warrior helmet appearance of the nose and forehead; and multiple other skeletal, cardiovascular, and urogenital defects. Cardiac manifestations are seen in $31 \%$ to $45 \%$ of cases and are responsible for nearly $35 \%$ of deaths in the first year of life. ${ }^{10,11}$ There is no discovered abnormality on chromosome 4 that is associated with AV block. Additionally, no channelopathies have been identified in connection with WHS such as mutations in the SCN5A and TRPM4 genes that have been shown to cause most cases of progressive familial heart block types IA and IB, respectively. ${ }^{12}$

Our patient was diagnosed with WHS during his first year of life, as he displayed decreased muscle tone and classic facial features at that time. Karyotyping revealed a partial deletion of the short arm of chromosome 4 . At the time of this case, he had outlived $95 \%$ of other patients with this condition. An echocardiogram did not reveal structural or congenital abnormalities. There are no reports in the literature of WHS patients with significant rhythm abnormalities. This may be secondary to the overall decreased longevity. To our knowledge, this is the first reported case of a person with WHS with third-degree AV block who underwent successful pacemaker implantation. A single-chamber VVI device was chosen to minimize the risk of lead dislodgement, as he would not be able to keep the arm immobilized. Consideration of pacemaker syndrome was contemplated, but, as the patient was immobile, this was deemed not to be an issue. In retrospect, this decision was likely the correct one, as the patient developed endocarditis due to single RV lead implantation. Perhaps, the use of a leadless pacemaker may have lessened this risk.

\section{Acknowledgment}

Special thanks to Dr. W. Michael Kutayli. 


\section{References}

1. Battaglia A, Carey JC, South ST. Wolf-Hirschhorn syndrome: a review and update. Am J Med Genet Part C Semin Med Genet. 2015;169(3):216-223.

2. Paradowska-Stolarz AM. Wolf-Hirschhorn syndrome (WHS)-literature review on the features of the syndrome. Adv Clin Exp Med. 2014;23(3):485-489.

3. Sifakis S, Manolakos E, Vetro A, et al. Prenatal diagnosis of Wolf-Hirschhorn syndrome confirmed by comparative genomic hybridization array: report of two cases and review of the literature. Mol Cytogenet. 2012;5:12.

4. Cooper H, Hirschhorn K. Apparent deletion of short arms of one chromosome ( 4 or 5 ) in a child with defects of midline fusion. Hum Chrom Newsl. 1961;4(14):14-16.

5. Shannon NL, Maltby EL, Rigby AS, Quarrell OW. An epidemiological study of Wolf-Hirschhorn syndrome: life expectancy and cause of mortality. J Med Genet. 2001;38(10):674-679.

6. Kevino. The Story of Jaap: Born in 1955. Available at: http:// wolfhirschhorn.org/2014/01/jaap/story-jaap-born-1955/. Accessed July 1, 2019.
7. Hirschhorn K, Cooper HL, Firschein IL. Deletion of short arms of chromosome $4-5$ in a child with defects of midline fusion. Humangenetik. 1965;1(5):479-482.

8. Basilico C, Moscatelli D. The FGF family of growth factors and oncogenes. Adv Cancer Res. 1992;59:115-165.

9. Stec I, Wright TJ, van Ommen GJB, et al. WHSC1, a $90 \mathrm{~kb}$ SET domain containing gene, expressed in early development and homologous to a Drosophila dysmorphy gene maps to the Wolf-Hirschhorn syndrome critical region and is fused to IgH in $\mathrm{t}(4 ; 14)$ multiple myloma. Hum Mol Genet. 1998;7(7):1071-1082.

10. Battaglia A, Filippi T, Carey JC. Update on the clinical features and natural history of Wolf-Hirschhorn (4p-) syndrome: experience with 87 patients and recommendations for routine health supervision. Am J Med Genet C Semin Med Genet. 2008;148C(4):246-251.

11. Von Elten K, Sawyer T, Lentz-Kapua S, Kanis A, Studer M. A case of Wolf-Hirschorn syndrome and hypoplastic left heart syndrome. Pediatr Cardiol. 2013;34(5):1244-1246.

12. Baruteau AE, Pass RH, Thambo JB, et al. Congenital and childhood atrioventricular blocks: pathophysiology and contemporary management. Eur J Pediatr. 2016;175(9):1235-1248. 